\title{
Modular Type III Porous Liquids based on Porous Organic Cage Microparticles
}

Aiting Kai, ${ }^{a}$ Benjamin D. Egleston, ${ }^{a}$ Rob Clowes, ${ }^{a}$ Michael E. Briggs, ${ }^{a}$ Andrew I Cooper ${ }^{a *}$ and Rebecca L. Greenaway ${ }^{\mathrm{a}, \mathrm{b}^{*}}$

${ }^{a}$ Department of Chemistry and Materials Innovation Factory, University of Liverpool, 51 Oxford Street, Liverpool, L7 3NY, UK

${ }^{\mathrm{b}}$ Department of Chemistry, Molecular Sciences Research Hub, Imperial College London, White City Campus, 82 Wood Lane, W12 0BZ, UK.

Email: aicooper@liverpool.ac.uk; r.greenaway@imperial.ac.uk

The dispersion of particulate porous solids in size-excluded liquids has emerged as a method to create Type III porous liquids, mostly using insoluble microporous materials such as metal-organic frameworks (MOFs) and zeolites. Here, we present the first examples of Type III porous liquids based on porous organic cages (POCs). By exploiting the solution processability of the POCs, racemic and quasiracemic cage microparticles were formed by chiral recognition. Dispersion of these porous microparticles in a range of size-excluded liquids, including oils and ionic liquids, formed stable POC-based Type III porous liquids. The flexible pairing between the solid POC particles and a carrier liquid allows the formation of a range of compositions, pore sizes, and other physicochemical properties to suit different applications and operating conditions. For example, we show that it is possible to produce porous liquids with relatively low viscosities (7-14 mpa-s) or high thermal stability $\left(325^{\circ} \mathrm{C}\right)$. A 12.5 wt. \% Type III porous liquid comprising racemic POC microparticles and an ionic liquid, [BPy] $\left[\mathrm{NTf}_{2}\right]$, shows a $\mathrm{CO}_{2}$ working capacity $\left(104.30 \mu \mathrm{mol} / \mathrm{g}_{\mathrm{L}}\right)$ that is significantly higher than the neat ionic liquid $\left(37.27 \mu \mathrm{mol} / \mathrm{g}_{\mathrm{L}}\right)$ between $25^{\circ} \mathrm{C}$ and $100{ }^{\circ} \mathrm{C}$. This liquid is colloidally stable and can be recycled at least 10 times without loss of $\mathrm{CO}_{2}$ capacity. 


\section{Introduction}

Porous liquids are a novel kind of porous material that are distinguished by their ability to flow. These materials have seen considerable progress since the concept was first introduced in 2007 by O'Reilly et al. ${ }^{[1]}$ Three types of porous liquids were initially proposed (Types I, II and II; Figure 1a) and after more than a decade, examples of each type have now been reported. ${ }^{[2]}$ Type I porous liquids are neat liquid substances with shape-persistent molecular porosity; Type II porous liquids are solutions of natively porous molecules dissolved in a 'non-porous' solvent, where the pores remain unoccupied because the solvent molecules are size excluded; Type III porous liquids are multiphase fluids, typically porous solids particles dispersed in sizeexcluded liquids. Type III porous liquids are typically simpler to prepare than the other two types, and this approach might prove to be more generalizable in the future. For Type I porous liquids, it is necessary to devise strategies for lowering the melting points of shape-persistent porous molecules, such as cages and macrocycles, and the viscosity of such liquids may also be limiting. Type II porous liquids are somewhat easier to access, though this requires strategies for increasing the solubility of the pore carriers in the size-excluded solvents, and again viscosity may be an issue at high concentrations of the pore carrier. By contrast, the formation of Type III porous liquids can be approached in a modular way, and it is feasible to screen a wide range of porous materials and bulky liquids to find suitable combinations. ${ }^{[3]}$ This modular approach might prove more industrially applicable, not least because one can draw on a large range of existing materials as building blocks, some of which have already been scaled up. ${ }^{[4]}$ So far, Type III porous liquids have mostly been constructed from metal-organic frameworks (MOFs) and zeolites. For example, ZIF-8 was found to be dispersible in several large hindered ionic liquids, ${ }^{[5-7]}$ or in polymeric glycols, ${ }^{[8]}$ while Cahir et al. reported the formation of a range of Type III porous liquids using various microporous solids, including MOFs and zeolites, in non-ionic oils. ${ }^{[3]}$ Until now, Type III porous liquids have been built from extended porous materials that are insoluble in common liquids.

Porous organic cages (POCs) are a type of molecular organic material that contains shape-persistent internal voids in the molecules that are accessible through windows. ${ }^{[9-11]}$ Imine-derived POCs can be synthesized in solution through a reversible condensation reaction, and many derivatives can be produced based on the selection of different synthetic precursors: a representative scheme for preparing the POCs used in this study is shown in Figure 1b. The window sizes and chemical environment of POCs can be tuned by introducing different functional groups into the precursors. ${ }^{[12]}$ POCs can also have good solubility in organic solvents, and are thus a candidate for preparing Type II porous liquids. ${ }^{[13-15]}$ There have also been attempts to decorate cages with long alkyl chain functionality to lower the melting points in the preparation of Type I porous liquids. ${ }^{[16,17]}$ Some of the properties of POCs can be retained when transferred into the liquid state, such as size-selective guest uptake, ${ }^{[18]}$ while others, such as chiral recognition, ${ }^{[14]}$ are lost. One potential way to retain the solid-state properties of POCs is to form Type III porous liquids, rather than Type I or Type II systems. 
a)
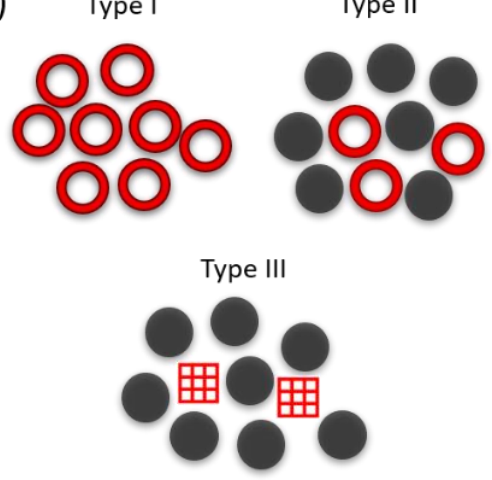

b)
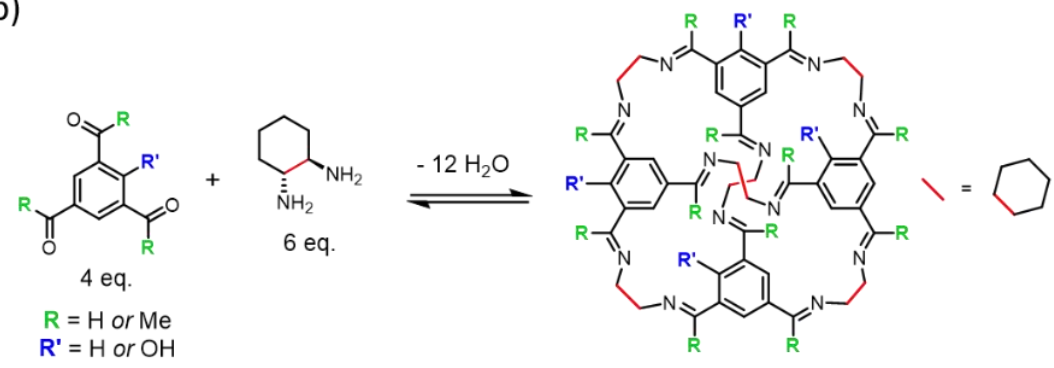

CC3: $R=H^{\prime}, R^{\prime}=H^{\prime}$

CC15: $\mathrm{R}=\mathrm{Me}, \mathrm{R}^{\prime}=\mathrm{H}$

CC19: $R=H, R^{\prime}=\mathrm{OH}$

c)

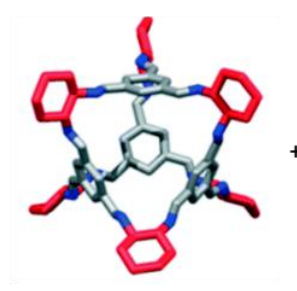

CC3- $R$

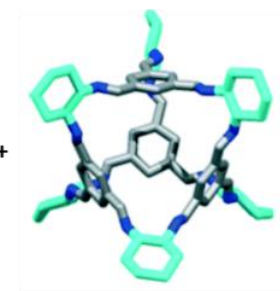

CC3-S $\underset{\text { Precipitation }}{\stackrel{\text { Solution Mixing }}{\longrightarrow}}$

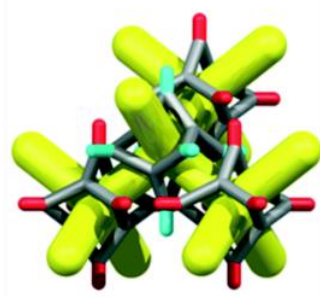

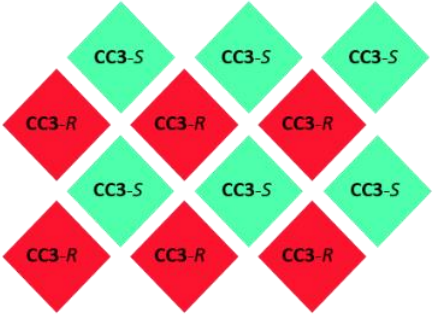

Figure 1: (a) Scheme showing the three classifications of porous liquids: Type I, Type II, and Type III; (b) General reaction scheme for the synthesis of CC3, CC15, and CC19, which are the POCs used to form microparticles in this study. Two cage enantiomers can be formed for each species; for example CC3- $R$ and CC3-S can be formed by using the different enantiomers of trans-1,2-cyclohexyldiamine (CHDA), ( $R, R$ )-CHDA, and ( $S, S)$-CHDA; (c) POCs such as CC3 can pack together window-to-window to form a $3 \mathrm{D}$ diamondoid pore network in the solid state by chiral recognition between the two cage enantiomers, which can be exploited to form POC microparticles for processing into Type III porous liquids. ${ }^{[19]}$

As a multiphase system, the colloidal stability of Type III porous liquids is an important consideration. For example, Dai et al. used hydrogen bonding between H-ZSM-5 zeolites and bulky phosphonium ionic liquids to construct a colloidally stable Type III system, ${ }^{[20]}$ whereas Li et al. and Liu et al. used surface functionalisation to coat particles of UiO-66 or Silicalite-1 respectively with solvent-similar polymeric groups to stabilise these as Type III porous liquids. ${ }^{[21,22]}$ More recently, the surface functionalisation method was also used to form a stabilised ZIF-67 dispersion, which can be used directly as a Type III porous liquid or conveniently processed further to form mixed matrix membranes with excellent selectivity between propane and propylene. ${ }^{[23]}$ While a 3D imine-linked covalent organic framework (COF) was functionalised with ionic liquid functionality on its outer shell, forming COF colloids that were extremely stable towards flocculation (> one year) in an ionic liquid. ${ }^{[24]}$ Alternatively, in ZIF-8 based Type III porous liquids, a rapid synthetic method can be employed to produce nanocrystalline particles that allow for stable emulsions when the solid ZIF- 8 is dispersed. ${ }^{[25]}$

POC nano- and micro-particles can also be easily fabricated from solution by exploiting the chiral recognition between two prefabricated homochiral precursor cages, producing co-crystals in a modular way without the 
use of any surfactants or templating agents. ${ }^{[19,26]}$ These can either be prepared from enantiomeric variants of the same cage species to form a racemate (Figure 1c), or formed from isostructural cage derivatives of opposite chirality to produce quasiracemic co-crystals. ${ }^{[27-29]}$ By using two chemically different cages to form quasiracemic co-crystals, it is possible to tune the properties of the pore carrier, such as the pore size or the chemical environment in the pores - for example, to produce materials with superior properties for quantum sieving of hydrogen isotopes. ${ }^{[30]}$ Furthermore, upon co-crystallisation, the solubility of these racemic and quasiracemic cage materials is often greatly reduced compared to the solution-processable enantiopure cage precursors, thus making them good candidates for preparing Type III porous liquids.

Here, we report the first use of POC assembled microparticles to form stable Type III porous liquids. Different compositions of cage microparticles (CC3-R/CC3-S, CC3-R/CC15-S, and CC3-R/CC19-S) were dispersed in a selection of size-excluded liquids including a range of oils and ionic liquids, and their gas uptakes were investigated. Overall, a versatile Type III porous liquid platform can be built using different POCs in neat liquids, without the need for any surfactants or post-synthetic modification, with physical properties that can be tailored according to the application.

\section{Results and Discussion}

\section{Synthesis and Characterisation of POC Microparticles}

First, the formation of three different POC microparticles was investigated: racemic CC3-R/CC3-S, quasiracemic CC3-R/CC15-S, and quasiracemic CC3-R/CC19-S (Figure 2a). The synthesis of CC3-R/CC3-S microparticles by chiral recognition was reported previously, where homochiral solutions of CC3- $R$ and CC3$S$ were mixed and uniformly fine microparticles were formed. ${ }^{[19]}$ Using a slight modification of that method, multiple large scale batches of CC3-R/CC3-S microparticles were formed by rapidly mixing dilute solutions of both CC3- $R$ and CC3-S in dichloromethane at room temperature with overhead stirring (Table 1, entries 1-5). Rapid precipitation of the POC microparticles was observed upon mixing, which were isolated by filtration. An additional batch of CC3-R/CC3-S was formed using a carefully controlled addition rate for comparison (Table 1, entry 6). We also investigated the formation of CC3-R/CC15-S, and CC3-R/CC19-S, with crystallisation of CC3-R/CC19-S occurring rapidly using the same method as with CC3-R/CC3-S (Table 1, entry 8). However, for CC3-R/CC15-S, rapid precipitation did not occur under these conditions; this is thought to be due to the methyl groups in $\mathbf{C C 1 5}$, which reduces the favourable interaction between the cage windows that promotes rapid co-crystallisation. Slater et al. generated co-crystals of CC3-R/CC15-S from dichloromethane using five-fold more concentrated solutions of the two cages, although small particle sizes were not targeted in that study. ${ }^{[12]}$ We found that microcrystalline particles of $C C 3-R / C C 15-S$ could be 
prepared at the same dilute concentration by changing the solvent to a 1:1 mixture of dichloromethane:methanol (Table 1, entry 7).

a)

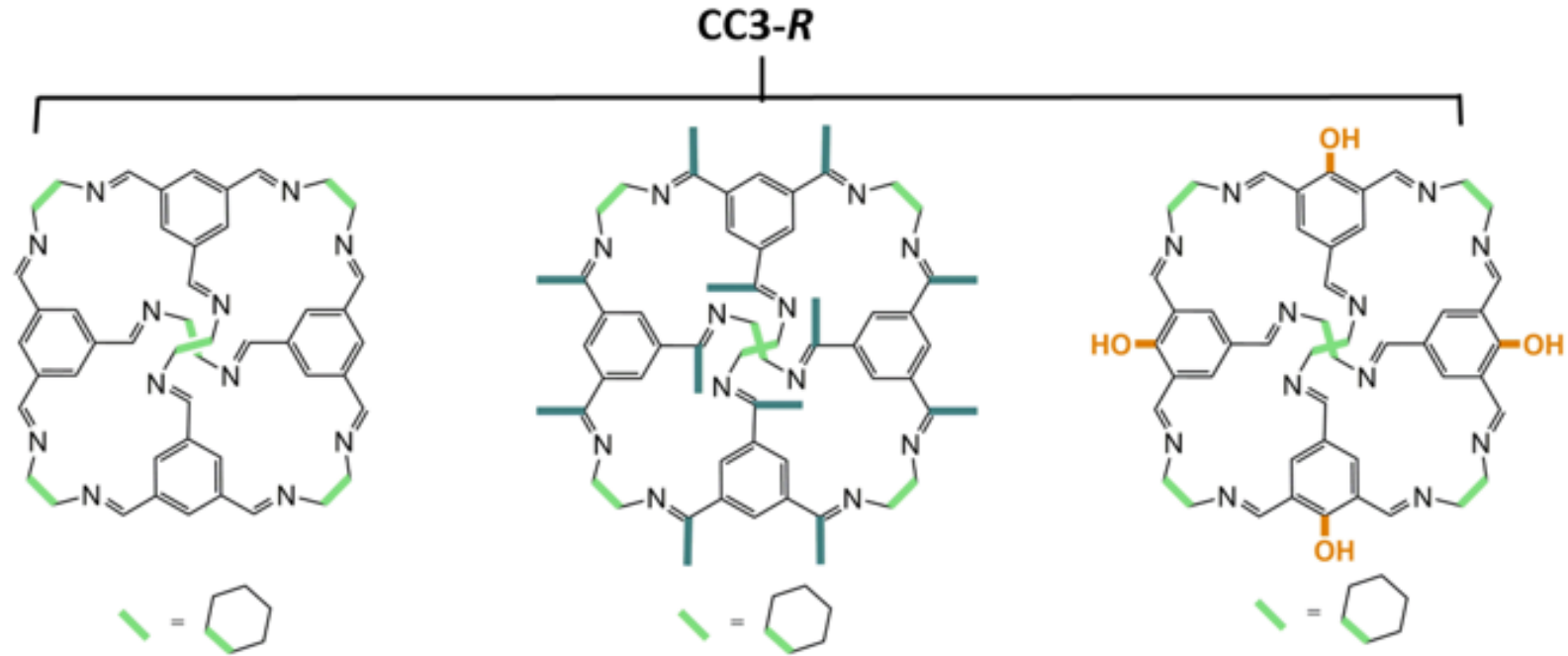

CC3-S

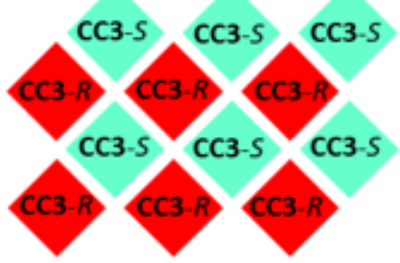

b)

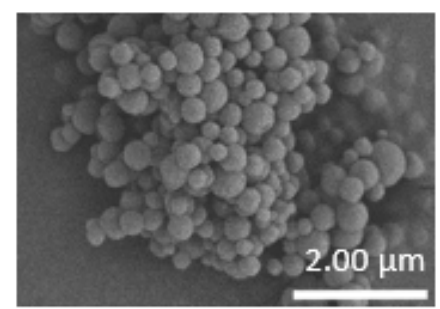

c)

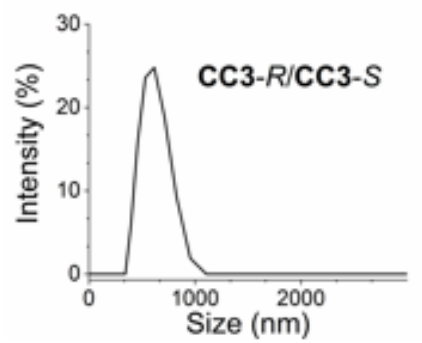

CC15-S
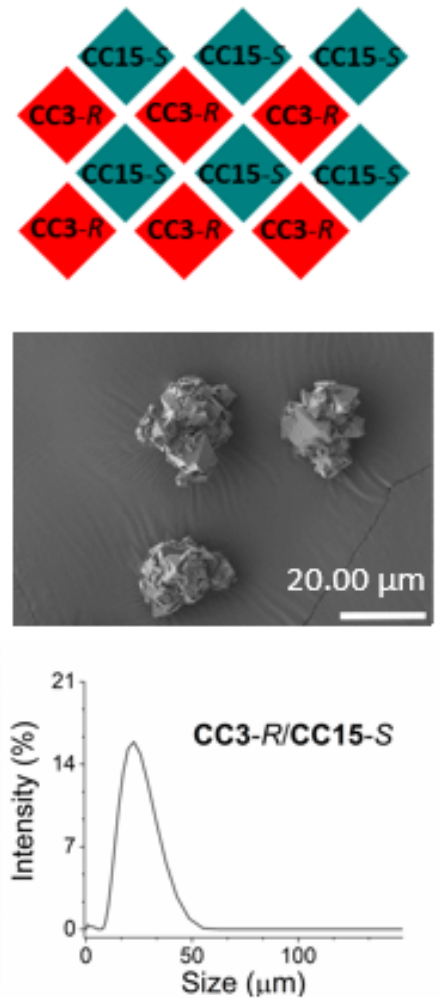

\section{CC19-S}
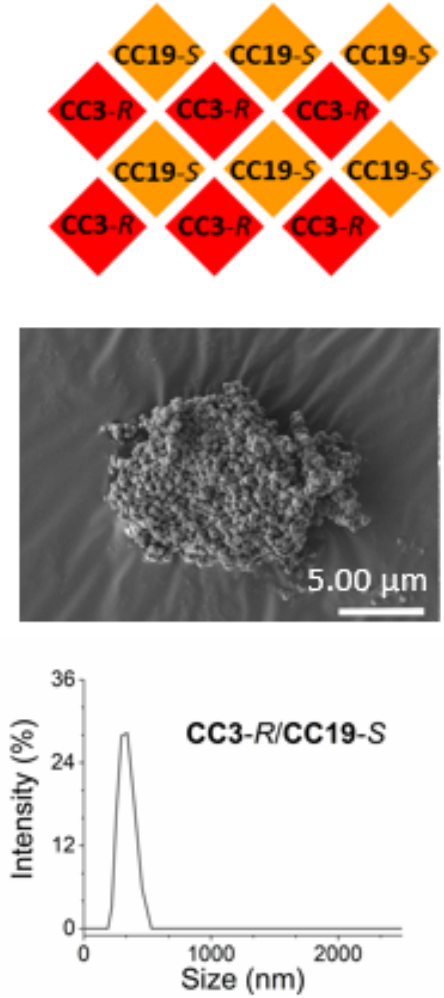

Figure 2: (a) Scheme for POC microparticle formation by combining CC3-R and with either CC3-S, CC15-S, or CC19-S; (b) Scanning electron micrographs for CC3-R/CC3-S, CC3-R/CC15-S, and CC3-R/CC19-S microparticles; (c) Particle size distributions of CC3-R/CC3-S (by DLS in dichloromethane), CC3-R/CC15-S (by SLS in EtOH), and CC3-R/CC19-S (DLS in dichloromethane). 
Analysis of these co-crystals confirmed they were the desired microparticles (Table 1), as determined by dynamic light scattering (DLS) measurements and scanning electron microscopy (SEM), with diameters for CC3- $R$ /CC3-S and CC3-R/CC19-S ranging from 200 $\mathrm{nm}$ to $1.5 \mu \mathrm{m}$ (Figure 2b-2c). The CC3-R/CC15-S particle size could not be measured using the solvents that we deployed for DLS because sedimentation occurred in $\mathrm{MeOH}$, while the co-crystal dissolved in dichloromethane. However, by using static light scattering (SLS) measurements, these particles were found to be significantly larger $(17 \mu \mathrm{m})$. This reflects the slower precipitation of these particles, which gives them the chance to increase in size. SEM also gave an indication of the particle morphology; when CC3-R/CC3-S was isolated after rapid mixing, the microparticles were spherical, whereas on slow addition, octahedral particles were formed (Figure S4). For CC3-R/CC19-S, SEM images also confirmed an octahedral morphology when using the rapid addition technique, whereas for CC3R/CC15-S, larger blocks of crystals with blended octahedral morphology were apparent, which corresponded to the larger particles observed by SLS (Figure S8). Analysis by powder x-ray diffraction (PXRD) showed results that were consistent with previous studies; the co-crystals had powder patterns that were similar to CC3 $\boldsymbol{\alpha}$, but with peak shifts that reflected smaller unit cell sizes (Figure S3). This indicates that all co-crystals adopt a window-to-window arrangement, with tighter packing due to the use of opposite cage enantiomers.

Table 1: Summary of the microparticle composition, particle sizes, and particle morphology.

\begin{tabular}{|c|c|c|c|c|}
\hline Entry & Composition & DLS Size / nm & SEM Size Range / nm & Morphology \\
\hline $\mathbf{1}$ & CC3- $R /$ CC3-S & 540 & $200-700$ & Spherical \\
\hline $\mathbf{2}$ & CC3- $R /$ CC3-S & 600 & $300-800$ & Spherical \\
\hline $\mathbf{3}$ & CC3- $R /$ CC3-S & 1200 & $300-1000$ & Spherical \\
\hline $\mathbf{4}$ & CC3- $R /$ CC3-S & 720 & $300-1000$ & Spherical \\
\hline $\mathbf{5}$ & CC3- $R /$ CC3-S & 630 & $200-800$ & Spherical \\
\hline $\mathbf{6}$ & CC3- $R /$ CC3-S & 940 & $200-1500$ & Octahedral \\
\hline $\mathbf{7}$ & CC3- $R /$ CC15-S & $17,000^{\mathrm{a}}$ & $8000-31000$ & Octahedral \\
\hline $\mathbf{8}$ & CC3- $R /$ CC19-S & 300 & $200-800$ & Octahedral \\
\hline
\end{tabular}

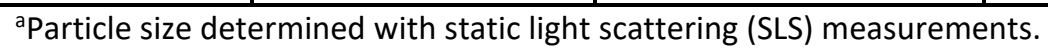

\section{Screening for Type III Porous Liquids using POC Microparticles}

We first carried out a screen for suitable size-excluded liquids to construct Type III porous liquids using the CC3-R/CC3-S microparticles (Table 1, entries 3 and 5 ). A range of liquids was selected, including different oils and ionic liquids (Figure 3a), some of which were reported previously to be size-excluded for MOFs and 
zeolites, such as silicone oil, pyridinium bis(trifluoromethanesulfonyl)imide ([BPy][NTf $]$ ), and trihexyltetradecylphosphonium bis(trifluoromethanesulfonyl)imide $\quad\left(\left[\mathrm{P}_{66614}\right]\left[\mathrm{NTf}_{2}\right]\right)$. $^{[3,6,7]}$ A 12.5 wt. \% dispersion of CC3-R/CC3-S microparticles was prepared in these liquids by mixing and sonication. For oils that were more viscous, such as Halocarbon $27^{\circledR}$ and Fomblin $Y^{\circledR}, 5$ wt. \% loadings were prepared to obtain a flowable dispersion. These dispersions were then screened for porosity to allow comparison of the gas uptakes with the neat, unadulterated liquids. Previously, analytical techniques such as IR and NMR spectroscopy, or gas displacement measurements, were used to probe the gas solubility in POC-derived Type II porous liquids. ${ }^{[13-15,18]}$ Here, the use of bulky liquids with high boiling points and low vapour pressures allowed us to study the gas solubility using more standard sorption measurements that are used for porous solids. Specifically, the use of a Quantachrome Nova instrument, benchmarked to known uptakes in liquids and with stirring to ensure that the liquids reached saturation uptake, allowed different gases to be screened and adsorption isotherms to be obtained (see ESI, Section 1, for more information).

Comparison of the $\mathrm{CO}_{2}$ uptakes at 1 bar in the neat liquids and the corresponding CC3-R/CC3-S dispersions (Table S3, Figure S9a-S9k) indicated that most of the dispersions showed a marked improvement in $\mathrm{CO}_{2}$ solubility over the neat liquid (Figure 3b). An exception was a 12.5 wt. \% dispersion in Genosorb $1753^{\circledR}$, where the neat liquid absorbed more $\mathrm{CO}_{2}$ than the dispersion, suggesting perhaps that the liquid molecules can occupy the pores in the CC3-R/CC3-S microparticles. It should also be noted that Genosorb liquids are designed specifically to absorb $\mathrm{CO}_{2}$, and hence have a relatively high native $\mathrm{CO}_{2}$ solubility in any case. The most marked increases in $\mathrm{CO}_{2}$ solubility were found with silicone oil ( $5 \mathrm{cSt}$ ), silicone oil AR 20, and [BPy] [NTf ${ }_{2}$ ]. Comparison of the measured uptakes with theoretical maximum uptakes for each dispersion, calculated by taking into account the proportions of the cage solid and the liquid (Table S4), found that $59-66 \%$ of the overall theoretical maximum porosity was obtained for these three liquids. The $5 \mathrm{wt}$ \% CC3-R/CC3-S dispersions in Halocarbon $27^{\circledR}$ and Fomblin $\gamma^{\circledast}$ also displayed $57-60 \%$ of the maximum theoretical porosity, but higher solid loadings led to highly viscous systems that did not flow. The remaining dispersions ranged from $25-46 \%$ of the maximum theoretical porosity. The observed reductions in uptake are likely due to the loss of some extrinsic porosity when CC3-R/CC3-S is dispersed, and the potential viscosities of each dispersion affecting the diffusion of gas through the system, but the increased uptakes indicated the successful formation of Type III porous liquids. Additionally, all of these dispersions were visually stable after standing at room temperature for at least 24 hours.

In order to gain a further understanding of these systems, the CC3-R/CC3-S dispersions in both silicone oil and $[\mathrm{BPy}]\left[\mathrm{NTf}_{2}\right]$ were selected for further studies. These $12.5 \mathrm{wt}$ \% dispersions illustrated the greatest enhancement in $\mathrm{CO}_{2}$ uptake over the neat liquids, for example, in silicone oil the dispersion illustrated a 2fold increase in capacity $\left(198 \pm 3.8 \mu \mathrm{mol} / \mathrm{g}_{\mathrm{L}} \mathrm{vs} .84 .8 \pm 2.4 \mu \mathrm{mol} / \mathrm{g}_{\mathrm{L}}\right.$ for pure silicone oil). A similar increase was also observed for the dispersion in $[\mathrm{BPy}]\left[\mathrm{NTf}_{2}\right]\left(172.1 \pm 3.6 \mu \mathrm{mol} / \mathrm{g}_{\mathrm{L}} \mathrm{Vs} .78 .3 \pm 4.5 \mu \mathrm{mol} / \mathrm{g}_{\mathrm{L}}\right.$ for pure 
[BPy][NTf $\left.\left.{ }_{2}\right]\right)$. These liquids also had the lowest viscosities in each class out of the oils and ionic liquids, allowing higher weight loadings to be studied.

a)

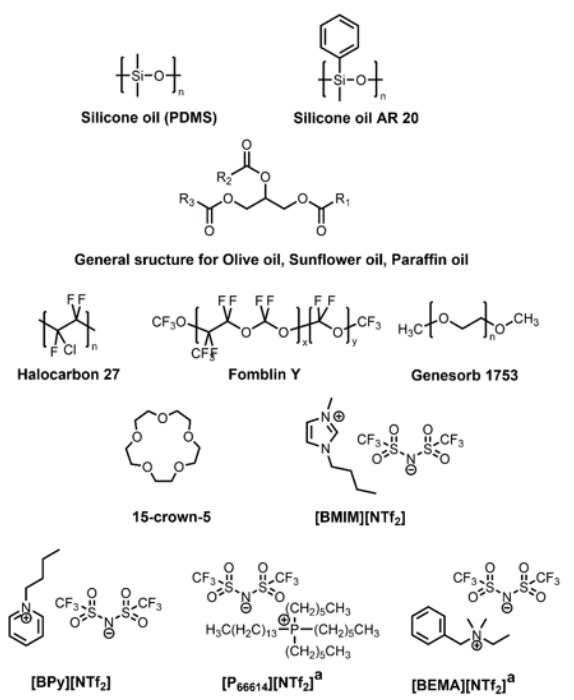

b)

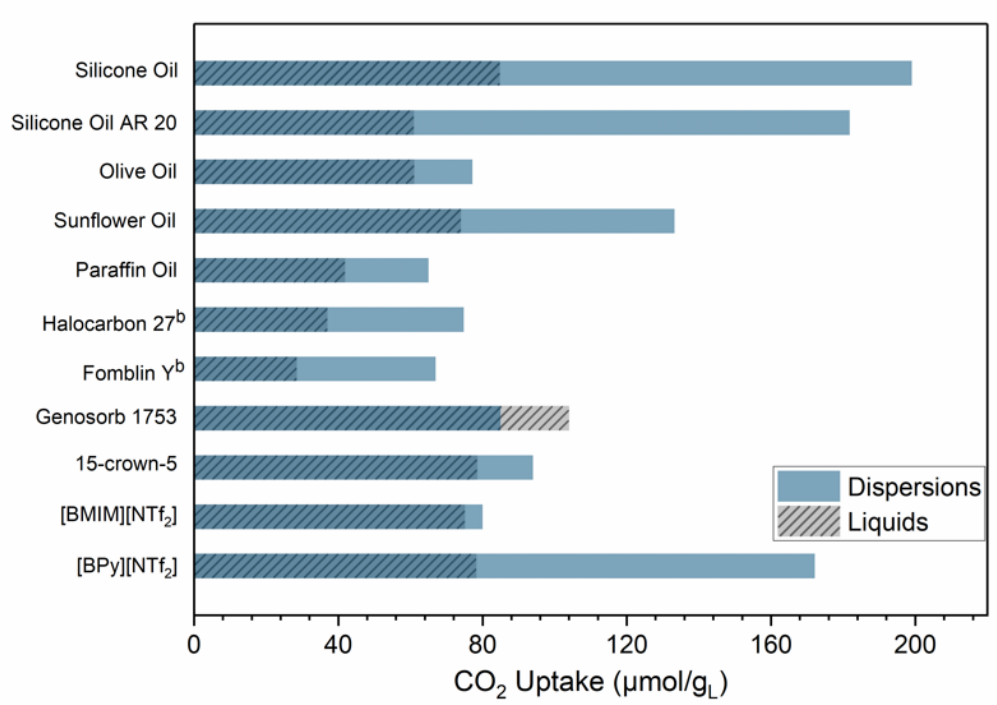

Figure 3: (a) Bulky liquids screened in this study for the formation of Type III porous liquids with CC3-R/CC3-S POC microparticles; (b) Comparison of the $\mathrm{CO}_{2}$ uptakes for the neat bulky liquids and corresponding $12.5 \mathrm{wt}$. \% dispersions of CC3-R/CC3-S. ${ }^{a}$ Ionic liquids screened with homochiral cage CC3 instead of CC3-R/CC3-S POC microparticles to determine if homochiral POCs can be used as a rapid indicator of size-exclusivity and porosity; ${ }^{\mathrm{b}} \mathrm{A} 5 \mathrm{wt}$. \% dispersion was studied to reduce viscosity.

\section{Comparison of Type III POC Microparticle Porous Liquids with Control Liquids}

In our preliminary screen, $C$ C3- $R / C$ C3-S dispersions led to similar gas uptake improvements in different liquids (e.g., silicone oil vs. [BPy][NTf 2 ; Figure 4a), indicating that the enhanced gas uptake was related to the CC3$R / C C 3-S$ microparticles introducing extra pore volume into the liquid. To further confirm that the observed improvement in $\mathrm{CO}_{2}$ uptake was due to the internal pore space of the $\mathrm{CC} 3-R / \mathrm{CC} 3-5$ microparticles, rather than, say, surface adsorption on the microparticles, a control molecule that mimics a fragment of the CC3 cage was synthesized (Figure $4 \mathrm{~b}$ inset). ${ }^{[14]}$ This non-porous control molecule does not dissolve in silicone oil or [BPy][NTf $f_{2}$, and thus can also be dispersed, allowing us to evaluate the effect of surface adsorption on the particles in the system. $\mathrm{CO}_{2}$ isotherms were measured on dispersions of the control molecule in both silicone oil and $[\mathrm{BPy}]\left[\mathrm{NTf}_{2}\right]$ for direct comparison with the CC3-R/CC3-S dispersions. No improvement in $\mathrm{CO}_{2}$ uptake was observed in either system, confirming that surface adsorption does not contribute measurably to the observed improvements in gas uptake (Figure 4b). Additionally, in contrast to the microparticle dispersions in the same liquids, dispersions of the control molecule were not stable, with sedimentation rapidly occurring ( $<1$ hour) on standing. 
Dispersions of homochiral cage CC3- $R$ in silicone oil, and CC3-S in [BPy] $\left[\mathrm{NTf}_{2}\right]$, were also investigated for their gas solubility - while similar gas uptakes were obtained compared to the CC3-R/CC3-S microparticle systems (Figure 4c), the homochiral dispersions were not as colloidally stable, with sedimentation occurring when stirring was not maintained at room temperature. However, this further confirms that these liquids are sizeexcluded from $\mathbf{C C}$, and that homochiral cages could be used to rapidly determine whether new liquids are size-excluded prior to forming POC microparticles with controlled particle sizes and narrow distributions. For example, measurement of the $\mathrm{CO}_{2}$ uptake in dispersions of CC3-S in $\left[\mathrm{P}_{66614}\right]\left[\mathrm{NTf}_{2}\right]$ and benzyl(ethyl)dimethylammonium bis(trifluoromethanesulfonyl)imide ([BEMA][NTf 2$]$ ) demonstrated that these two ionic liquids were size-excluded (Figure 3a, Figure S9I-S9m).

Finally, different batches of CC3-R/CC3-S microparticles were investigated to evaluate the effects of particle size and surface morphology on the gas uptake. Dispersions of CC3-R/CC3-S with particle sizes of $600 \mathrm{~nm}$ and $720 \mathrm{~nm}$ (Table 1, entry 2 and 4) show similar $\mathrm{CO}_{2}$ solubility compared to dispersions with particle sizes of $1200 \mathrm{~nm}$ and $630 \mathrm{~nm}$ (Table 1, entry 3 and 5), in silicone oil and [BPy][NTf 2 respectively (Figure 4a). When CC3-R/CC3-S with an octahedral morphology (Table 1, entry 6) was used, its dispersion presented similar gas uptakes to spherical CC3-R/CC3-S microparticles (Figure 4d). Overall, this shows that the particle size and morphology has little if any effect on the gas uptake of the dispersions, but that controlling the particle size is important for ensuring good, long-term dispersion stability. 
a)

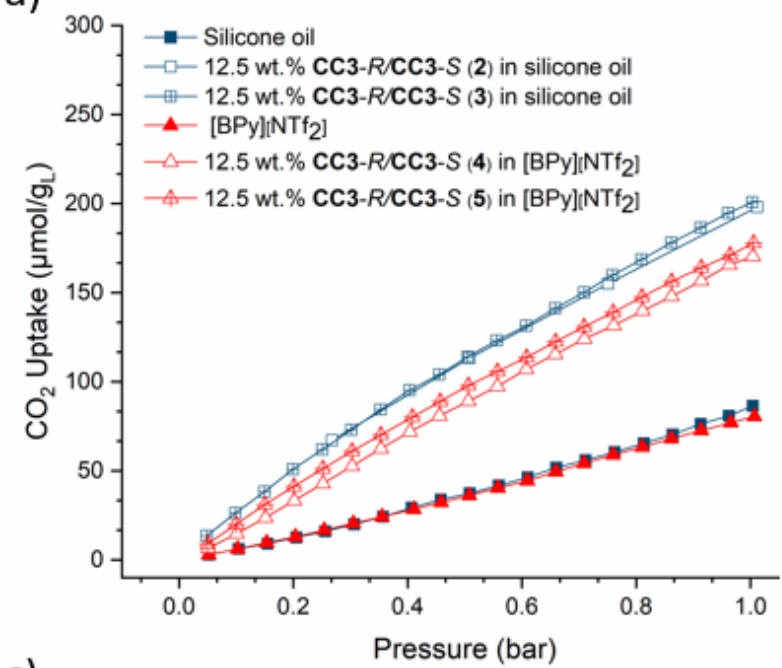

c)

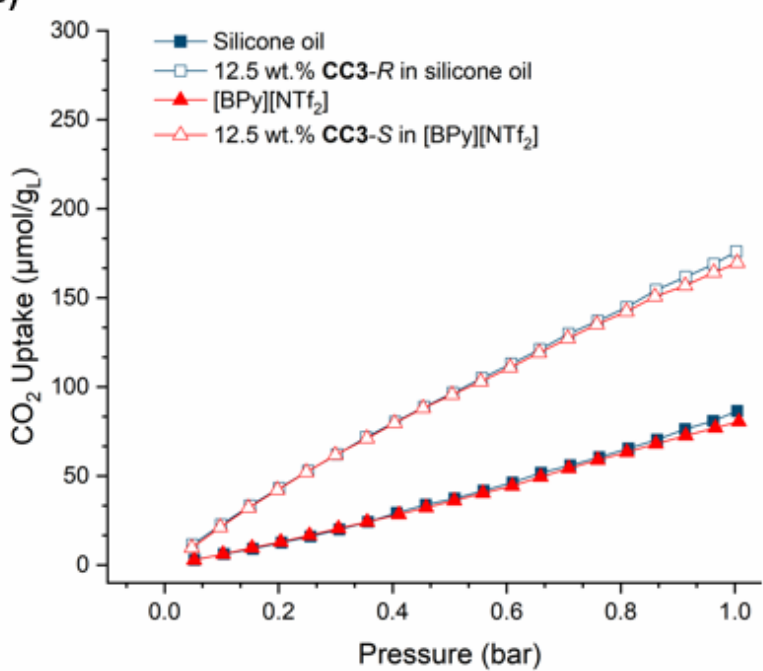

b)

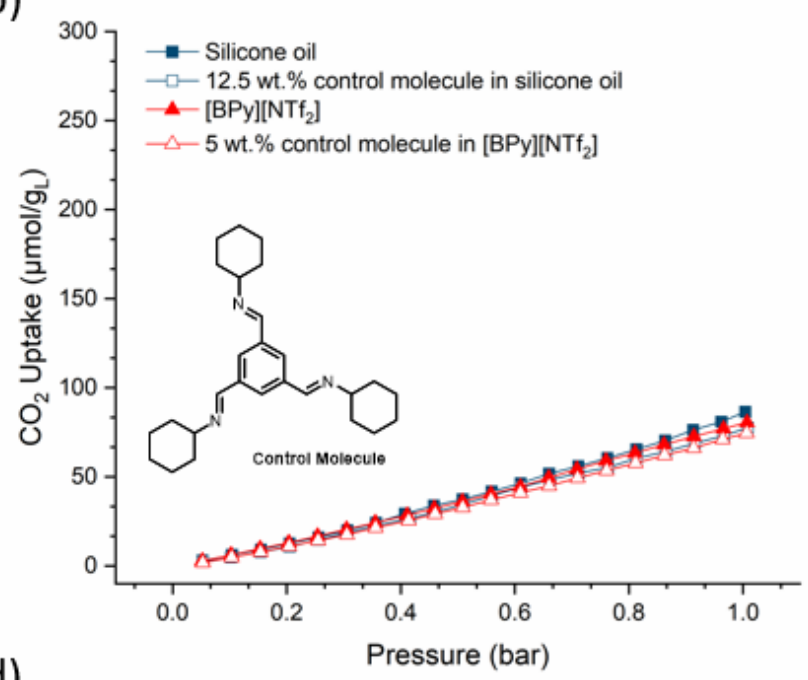

d)

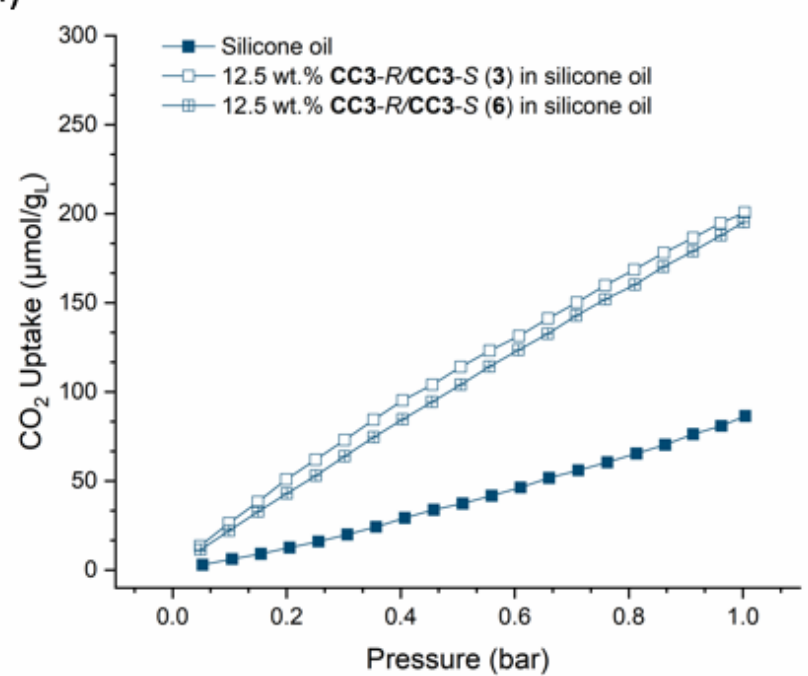

Figure 4: (a) $\mathrm{CO}_{2}$ adsorption isotherms of $12.5 \mathrm{wt}$. \% dispersions of CC3-R/CC3-S with varying particle sizes in silicone oil and [BPy] $\left[\mathrm{NTf}_{2}\right]$; (b) $\mathrm{CO}_{2}$ adsorption isotherms of non-porous control molecule dispersions in silicone oil and [BPy][NTf 2 , with inset showing the structure of the control molecule; (c) $\mathrm{CO}_{2}$ adsorption isotherms of homochiral cage $\mathrm{CC} 3$ dispersions in silicone oil and [BPy] $\left[\mathrm{NTf}_{2}\right]$; (d) $\mathrm{CO}_{2}$ adsorption isotherms of $12.5 \mathrm{wt}$. \% dispersions of CC3-R/CC3-S with different particle morphologies in silicone oil. The numbers in brackets indicate the batch of microparticles used from Table 1.

\section{Gas Uptake, properties and stability of Type III CC3-R/CC3-S Microparticle Porous Liquids}

To be put into practical use, porous liquids should offer favourable characteristics, such as being recyclable and thermally stable. We selected two systems from the initial screen-CC3-R/CC3-S in silicone oil and in [BPy] $\left[\mathrm{NTf}_{2}\right]$ - to more fully study their physicochemical properties. Different loadings of CC3-R/CC3-S microparticles $(5,12.5$, and $20 \mathrm{wt}$. \%) were prepared in both liquids to evaluate the effect of microparticle concentration on both the gas uptake and the dispersion viscosity.

The viscosity of the dispersions in $[\mathrm{BPy}]\left[\mathrm{NTf}_{2}\right]$ was higher than those in silicone oil (Table 2), which is due to the general viscous nature of ionic liquids. ${ }^{[28]}$ However pure $[\mathrm{BPy}]\left[\mathrm{NTf}_{2}\right]$ has a viscosity of $67.34 \mathrm{mpa} \cdot \mathrm{s}$, which 
is substantially lower than the viscosity of other size-excluded ionic liquids; for example, $\left[\mathrm{P}_{66614}\right]\left[\mathrm{NTf}_{2}\right]$ and [BEMA][NTf ${ }_{2}$ ] have viscosities of $395.7 \mathrm{mpa} \cdot \mathrm{s}$ and $496.6 \mathrm{mpa} \cdot \mathrm{s}$, respectively. Viscosity studies on the $5,12.5$, and 20 wt. \% dispersions of CC3-R/CC3-S microparticles in [BPy][NTf $\left.{ }_{2}\right]$ and in silicone oil showed that the viscosity of the dispersions increased with increasing particle concentration (Table 2). However, while the ionic liquid dispersions had relatively higher viscosities, which could slow down gas adsorption kinetics, the saturated gas solubilities appeared to be unaffected: both $\mathrm{CO}_{2}$ and $\mathrm{CH}_{4}$ uptakes increased linearly with increasing CC3-R/CC3-S content from 0 to $20 \mathrm{wt}$ \% for both the [BPy] $\left[\mathrm{NTf}_{2}\right]$ and silicone oil based dispersions (Figure 5a, Figure S10-S13). At $20 \mathrm{wt}$. \% the uptakes were fairly comparable across both systems, although the overall uptakes for both gases were slightly higher in the silicone oil dispersion $\left(\mathrm{CO}_{2}: 280 \mu \mathrm{mol} / \mathrm{g}_{\mathrm{L}} \mathrm{vs} 210\right.$ $\mu \mathrm{mol} / \mathrm{g}_{\mathrm{L}} ; \mathrm{CH}_{4}: 121 \mu \mathrm{mol} / \mathrm{g}_{\mathrm{L}}$ vs $\left.103 \mu \mathrm{mol} / \mathrm{g}_{\mathrm{L}}\right)$. Dispersions of CC3-R/CC3-S in silicone oil were also investigated up to $50 \mathrm{wt}$ \%, with a linear trend for $\mathrm{CO}_{2}$ adsorption again being observed up to $635 \mu \mathrm{mol} / \mathrm{g}_{\mathrm{L}}$ at $50 \mathrm{wt}$. \% (Figure $5 b$ and S14).

The dispersion in $[\mathrm{BPy}]\left[\mathrm{NTf}_{2}\right]$ demonstrates good thermal stability according to thermal gravimetric analysis (TGA, Figure $5 \mathrm{c}$ ), with no significant mass loss observed until $325^{\circ} \mathrm{C}$. However, the low viscosity silicone oil used in these studies (PDMS, $5 \mathrm{mpa} \cdot \mathrm{s})$ has a significantly higher vapour pressure $(<700 \mathrm{~Pa} \text { at } 298.15 \mathrm{~K})^{[31]}$ compared to $[\mathrm{BPy}]\left[\mathrm{NTf}_{2}\right](0.0519 \mathrm{~Pa}$ at $498.07 \mathrm{~K}),{ }^{[32]}$ and the corresponding porous liquid therefore demonstrates a much lower thermal stability, with mass loss occurring from $60^{\circ} \mathrm{C}$ based on TGA analysis (Figure S15). This does not cause significant problems for the gas sorption measurements carried out here, with the degassing and uptake measurements performed immediately after sample preparation at ambient temperature, but this increased volatility might account for the slightly elevated $\mathrm{CO}_{2}$ adsorption isotherm of a 12.5 wt. \% silicone oil dispersion after 1 month compared to after 1 day, possibly due to slow evaporation of the liquid over time making the porous liquid more concentrated, while the gas uptake remained nearly unchanged for the aged [BPy][NTf 2$]$ sample (Figure $5 \mathrm{~d}$ ).

For these two systems, the viscosity and thermal stability are essentially trade-offs; ideally, one would like a high thermal stability liquid with low viscosity to allow the broadest range of potential applications. We note that the thermal stability limit is imposed by the liquid, rather than the POC. 
Table 2: Summary of viscosity measurements on the liquids and different concentration dispersions investigated.

\begin{tabular}{|c|c|c|c|c|}
\hline \multirow{2}{*}{ Liquids } & \multicolumn{4}{|c|}{ Viscosity (mpa·s) } \\
\cline { 2 - 5 } & $\begin{array}{c}\mathbf{0} \text { wt. \% } \\
\text { Dispersion }\end{array}$ & $\begin{array}{c}\mathbf{5} \text { wt. \% } \\
\text { Dispersion }\end{array}$ & $\begin{array}{c}\mathbf{1 2 . 5} \text { wt. \% } \\
\text { Dispersion }\end{array}$ & $\begin{array}{c}\mathbf{2 0} \text { wt. \% } \\
\text { Dispersion }\end{array}$ \\
\hline Silicone Oil & $5.01 \pm 0.01$ & $7.41 \pm 0.09$ & $13.22 \pm 0.55$ & $19.09 \pm 0.60$ \\
\hline$[\mathrm{BPy}]\left[\mathrm{NTf}_{2}\right]$ & $67.34 \pm 0.06$ & $86.18 \pm 0.16$ & $142.2 \pm 0.14$ & $303.5 \pm 0.29$ \\
\hline
\end{tabular}

a)

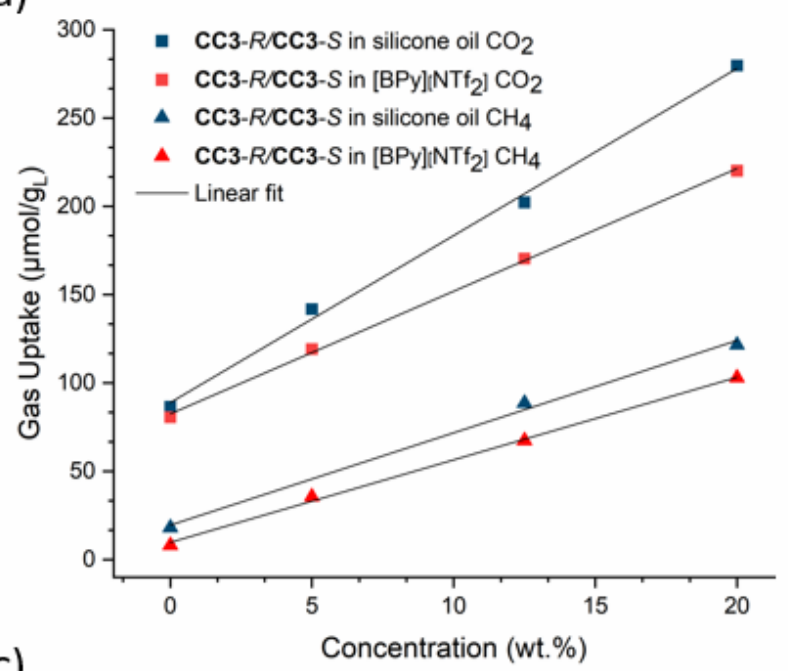

c)

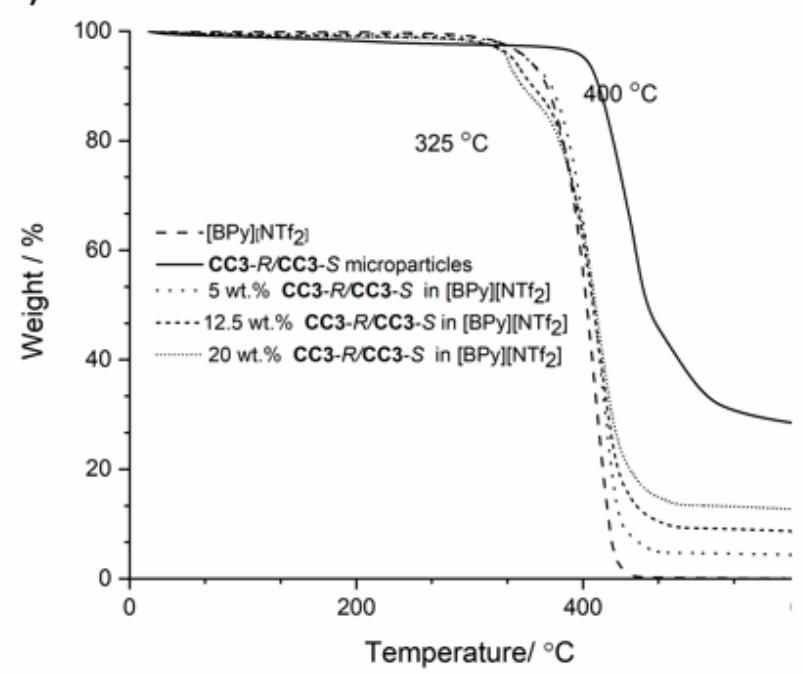

b)

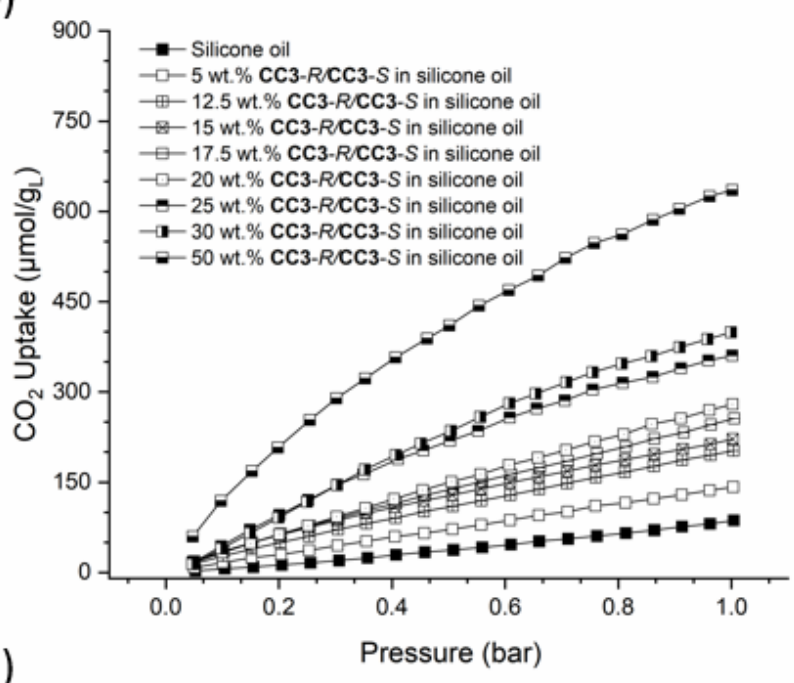

d)

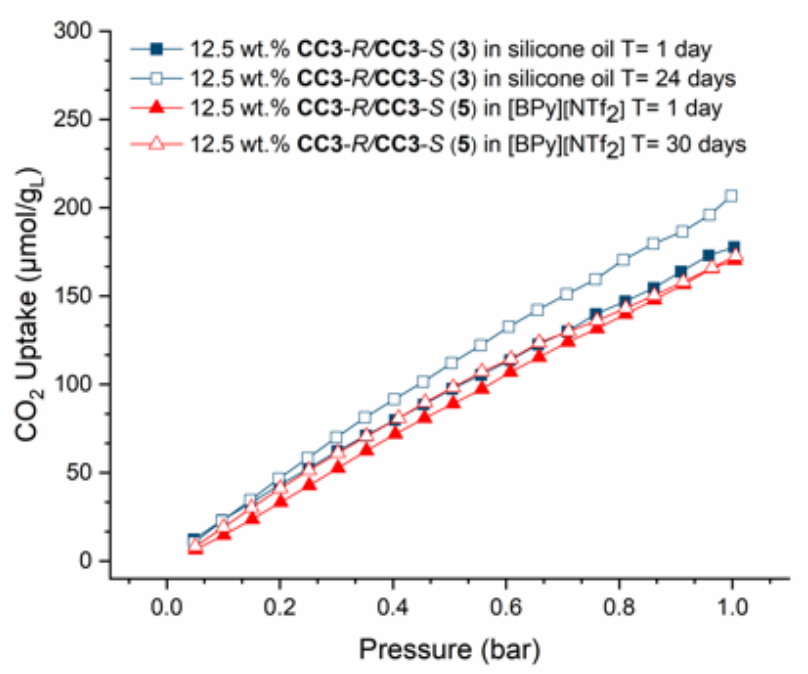

Figure 5: (a) Measured gas uptakes for a range of CC3-R/CC3-S dispersions at different concentrations (1 bar, 298-300 $\mathrm{K})$; (b) $\mathrm{CO}_{2}$ adsorption isotherms of silicone oil and the corresponding 5, 12.5, 15, 17.5, 20, 30 and $50 \mathrm{wt}$. \% dispersions of CC3-R/CC3-S microparticles; (c) TGA of [BPy][NTf ${ }_{2}$ ] and 5, 12.5 and 20 wt. \% CC3-R/CC3-S dispersions in [BPy][NTf ]; $^{2}$ (d) $\mathrm{CO}_{2}$ adsorption study of aged dispersion samples. 
While there is a trade-off between the viscosity and thermal stability for dispersions in silicone oil (PDMS, 5 $\mathrm{mpa} \cdot \mathrm{s})$ vs $[\mathrm{BPy}]\left[\mathrm{NTf}_{2}\right]$, the other physical properties for these two porous liquids are broadly similar. Both systems retain their porosity over time (Figure $5 \mathrm{~d}$ ). To evaluate the recyclability of these liquids as gas sorbents, the $\mathrm{CO}_{2}$ uptake was measured over 10 cycles in a 12.5 wt. \% dispersion of CC3-R/CC3-S in [BPy][NTf ${ }_{2}$ (Figure 6a and Figure S16), with re-activation by vacuum degassing for 100 minutes carried out between measurements. The $\mathrm{CO}_{2}$ uptakes were reproducible, with no loss in uptake apparent over repeated cycles (average $\mathrm{CO}_{2}$ uptake over 10 cycles: $174.3 \pm 4.6 \mu \mathrm{mol} / \mathrm{g}$ ). Due to the slight volatility of the silicone oil, the corresponding $12.5 \mathrm{wt}$. \% dispersion was only cycled twice, but again, the $\mathrm{CO}_{2}$ solubility was completely reproducible over two cycles (Figure S17).

The cage microparticle and phase stability of both dispersions was also investigated in more detail. The crystallinity of the CC3-R/CC3-S microparticles was retained upon formation of dispersions in silicone oil and [BPy] $\left[\mathrm{NTf}_{2}\right]$ (Figure S18-S19), and no phase change was observed post-sorption (Figure S20). Both the silicone oil and $[\mathrm{BPy}]\left[\mathrm{NTf}_{2}\right]$ dispersions of $\mathrm{CC} 3-R / \mathrm{CC} 3-S$ microparticles appeared to be visually stable over extended periods. To quantify the dispersion stability, a LUMiSizer $^{\circledast}$ was used to accelerate the creaming or sedimentation process for $12.5 \mathrm{wt}$. \% dispersions of CC3-R/CC3-S (particle size: 500-700 nm) in both silicone oil and $[\mathrm{BPy}]\left[\mathrm{NTf}_{2}\right] \cdot{ }^{\left[{ }^{[3]}\right.}$ According to Stoke's law, particle size plays an important role in determining the ratio of gravitational to Brownian forces applied to the particles in a dispersion, and hence reducing the particle size can help to control the sedimentation velocity and thus stabilise multiphase systems. ${ }^{[34]}$ At a relative centrifugal force of $532 \times \mathrm{g}$, the CC3-R/CC3-S microparticles separate by creaming to the surface of the silicone oil at a sedimentation velocity of $0.24 \mathrm{~mm} /$ day, indicating that the dispersion is stable (Table S7, Figure S21). The [BPy][NTf $]$ system also showed creaming but had a reduced sedimentation velocity of 0.04 $\mathrm{mm} /$ day, indicating that this dispersion has improved stability over the one in silicone oil (Table S7, Figure S23). This could be due to the increased viscosity of the ionic liquid, or potentially because the cation and anion of $[\mathrm{BPy}]\left[\mathrm{NTf}_{2}\right]$ provide electrostatic stabilization for the POC particles. ${ }^{[35]}$

Finally, the increased thermal stability of [BPy][NTf $\left.{ }_{2}\right]$ allowed for further adsorption studies to be carried out at higher temperatures to investigate the potential of a temperature-swing process for gas uptake and release. The $\mathrm{CO}_{2}$ uptakes of neat [BPy] $\left[\mathrm{NTf}_{2}\right]$ and its corresponding $12.5 \mathrm{wt}$ \% CC3-R/CC3-S dispersion were measured at a range of temperatures: $25,40,60,80$ and $100{ }^{\circ} \mathrm{C}$ (Figure 6b, and Figures S24-S25). Both systems showed measurable uptakes, even when the temperature was increased to $100{ }^{\circ} \mathrm{C}$, which might arise from the strong interaction of $\mathrm{CO}_{2}$ with the ionic liquid, but the working absorption capacity of CC3$R /$ CC3-S in [BPy] $\left[\mathrm{NTf}_{2}\right]$ was significantly larger than for neat [BPy][NTf $\left.{ }_{2}\right]\left(104.30 \mu \mathrm{mol} / \mathrm{g}_{\llcorner} \mathrm{Vs} 37.27 \mu \mathrm{mol} / \mathrm{g}_{\mathrm{L}}\right.$ between $25^{\circ} \mathrm{C}$ and $100{ }^{\circ} \mathrm{C}$ ). 
a)

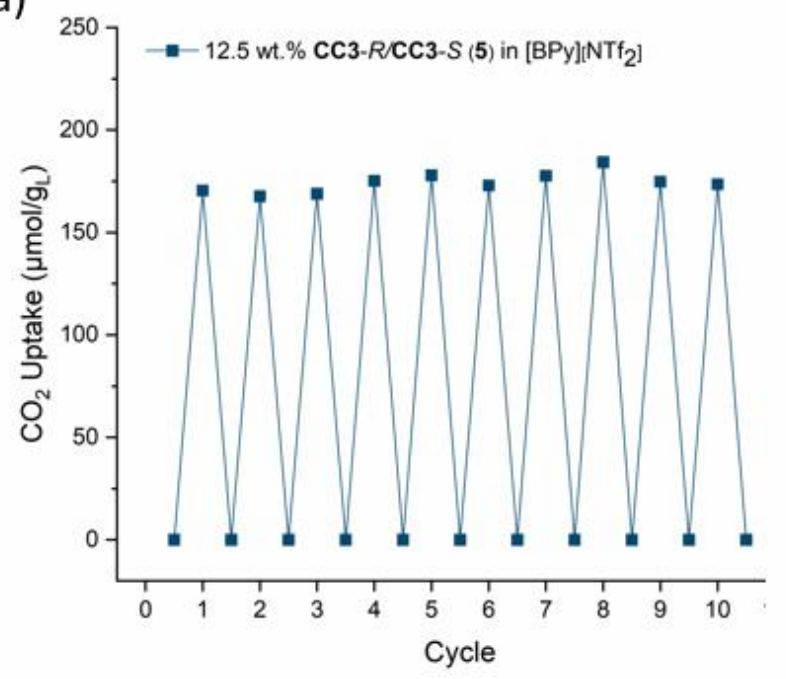

b)

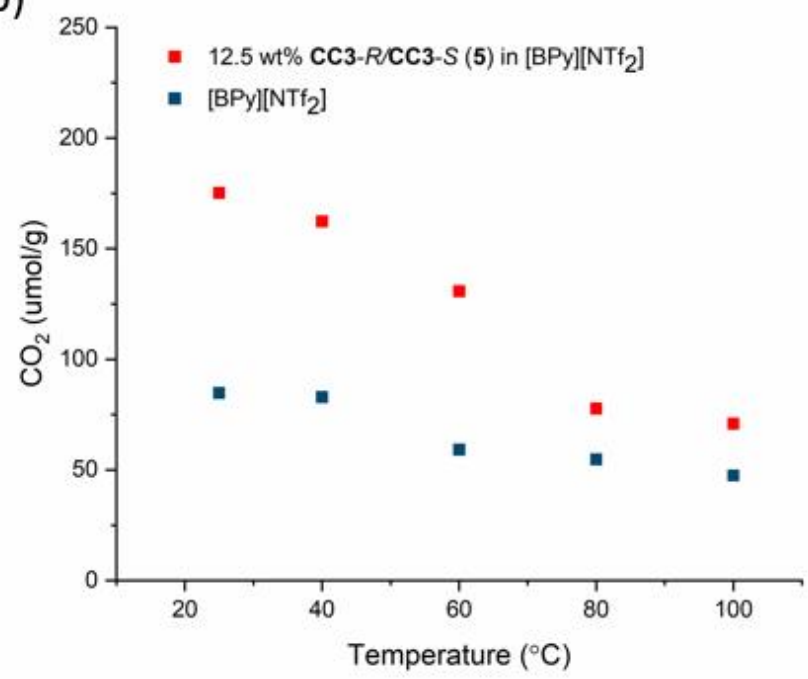

Figure 6: (a) Recycling study for $\mathrm{CO}_{2}$ uptake (1 bar, 298-300 $\mathrm{K}$ ) in a $12.5 \mathrm{wt}$. \% dispersion of CC3-R/CC3-S in [BPy] [NTf 2 ]; (b) $\mathrm{CO}_{2}$ solubilities in $[\mathrm{BPy}]\left[\mathrm{NTf}_{2}\right]$ and the corresponding $12.5 \mathrm{wt}$. \% CC3-R/CC3-S dispersion at $25,40,60,80$, and $100{ }^{\circ} \mathrm{C}$. The Type III porous liquid has a higher working capacity $\left(104.30 \mu \mathrm{mol} / \mathrm{g}_{\mathrm{L}}\right)$ than the neat ionic liquid $\left(37.27 \mu \mathrm{mol} / \mathrm{g}_{\mathrm{L}}\right)$ between $25^{\circ} \mathrm{C}$ and $100{ }^{\circ} \mathrm{C}$.

\section{Modification of porosity in Type III PLs by the modular assembly of two POCs into microparticles}

Controlling POC pore structure to influence the gas uptake has been studied widely in the solid state, for example by introducing bulky groups to decrease the window or cavity sizes, as applied in Xe or hydrogen isotope separation. ${ }^{[12,30]}$ Likewise, specific functional groups have been introduced into POCs to modulate the chemical environment for $\mathrm{CO}_{2} / \mathrm{CH}_{4}$ separations. ${ }^{[26]}$ This concept was also recently translated to the liquid state in Type II porous liquids with POCs that dissolve in bulky organic solvents. ${ }^{[18]}$ Here, we sought to transfer this concept to Type III porous liquids by using quasiracemic cocrystals.

Two systems were studied: CC3-R/CC15-S and CC3-R/CC19-S (Figure 2a). CC15 is isostructural with CC3, but methyl groups occupy the four windows and reduce the window size to $1.7 \AA$ (from $4 \AA$ in CC3). ${ }^{[18]}$ The reduced cage window size in CC15 affects gas sorption in the internal cavities and in the portal sites, with the methyl groups both excluding larger guests and interfering with electrostatic interactions of guest molecules with the imine bonds. For example, $\mathrm{CO}_{2}$ and Xe uptakes in $\mathbf{C} 15$ were approximately half as large as for CC3 in the solid state, ${ }^{[12]}$ and this occlusion was even more pronounced in a CC15-derived Type II porous liquid, where the Xe uptake was almost shut off entirely. ${ }^{[18]}$ CC19 has an analogous molecular structure, but with one hydroxyl group attached to each of its four aromatic rings. The incorporation of these polar hydroxyl groups improves the $\mathrm{CO}_{2}$ uptake in the solid state compared to $\mathbf{C C}$, while lowering $\mathrm{CH}_{4}$ uptakes. ${ }^{[26]}$ Hence, by incorporating either CC15 or CC19 into the microparticles, there is an opportunity to tune the gas selectivity in the corresponding Type III porous liquids. 
As might be expected, both the $\mathrm{CO}_{2}$ and $\mathrm{CH}_{4}$ uptakes in the $12.5 \mathrm{wt}$. \% dispersion of CC3-R/CC15-S in silicone oil were significantly reduced compared to the CC3-R/CC3-S liquid $\left(\mathrm{CO}_{2}: 68.5 \pm 1.3 \mu \mathrm{mol} / \mathrm{g}_{\mathrm{L}}\right.$ vs $198.0 \pm 3.8$ $\mu \mathrm{mol} / \mathrm{g}_{\mathrm{L}} ; \mathrm{CH}_{4}: 30.2 \pm 0.3 \mu \mathrm{mol} / \mathrm{g}_{\mathrm{L}} \mathrm{vs} 105.2 \pm 16.5 \mu \mathrm{mol} / \mathrm{g}_{\mathrm{L}}$ ). By contrast, a slightly higher $\mathrm{CO}_{2}$ uptake, and broadly comparable $\mathrm{CH}_{4}$ uptake, were observed in the $12.5 \mathrm{wt}$. \% dispersion of CC3-R/CC19-S in silicone oil $\left(\mathrm{CO}_{2}: 210.3 \pm 3.3 \mu \mathrm{mol} / \mathrm{g}_{\mathrm{L}} ; \mathrm{CH}_{4}: 117.4 \pm 21.4 \mu \mathrm{mol} / \mathrm{g}_{\mathrm{L}}\right.$ ) (Figure S26-S28). The reduction in porosity upon introducing CC15-S is likely due to the methyl groups blocking the cage windows. While incorporation of CC19 into the microparticles improved gas uptakes in the Type III porous liquids, no significant enhancement in $\mathrm{CO}_{2} / \mathrm{CH}_{4}$ selectivity was observed, unlike in the solid state. This is probably due to its homogeneous distribution in the CC3-R/CC19-S microparticles, because previous studies ${ }^{[26]}$ found that $\mathrm{CO}_{2} / \mathrm{CH}_{4}$ selectivity only occurred when CC19 was included in a core-shell morphology. The use of such core-shell co-crystals to form selective Type III porous liquids is a subject for future studies.

\section{Conclusions}

We present here the first Type III porous liquids based on the dispersion of POC microparticles prepared by chiral recognition between chirally-opposed isostructural cages. A selection of size-excluded carrier liquids was investigated, including oils and ionic liquids, which can be used to tailor the porous liquids to meet application requirements. We were able to access liquids with relatively low viscosity, high thermal stability, or good recyclability, while maintaining properties such as gas solubility and colloidal stability. A 12.5 wt. \% CC3-R/CC3-S dispersion in silicone oil or [BPy][NTf $\left.{ }_{2}\right]$ showed an approximate 2-fold increase in $\mathrm{CO}_{2}$ uptake over the neat silicone oil, and up to 8 times the $\mathrm{CH}_{4}$ uptake. These POC microparticle dispersions maintained their gas adsorption properties for at least one month and showed good colloidal stability. CC3-R/CC3-S dispersions in [BPy] $\left[\mathrm{NTf}_{2}\right]$ suffered no mass loss until $325^{\circ} \mathrm{C}$, and demonstrated a working capacity of 104.30 $\mu \mathrm{mol} / \mathrm{g}_{\mathrm{L}}$ by temperature swing $\left(25-100{ }^{\circ} \mathrm{C}\right)$. These liquids were recyclable over at least ten $\mathrm{CO}_{2}$ adsorption/desorption cycles. The incorporation of $\mathrm{CC15}$ into the microparticles reduced the $\mathrm{CO}_{2}$ and $\mathrm{CH}_{4}$ uptakes significantly, while inclusion of CC19 increased the uptake of these gases, demonstrating the feasibility of fine-tuning gas sorption properties in Type III porous liquids by changing the microparticle components. Other potential applications for the future include the separation of volatile organic compounds or chiral separations using POC porous liquids. ${ }^{[36,37]}$ 


\section{Acknowledgements}

We thank the Engineering and Physical Sciences Research Council (EPSRC) under the Grant EP/R005710/1 for financial support. A.K. thanks the China Scholarship Council for a PhD studentship. R.L.G. thanks the Royal Society for a University Research Fellowship. We acknowledge the MicroBioRefinery for assistance with QTOF-MS measurements, and Dr Marc Little for carrying out the PXRD measurements on the cage microparticles and Type III porous liquids. We thank Dr. Tom Hasell (University of Liverpool) and Prof. Stuart James (Queen's University Belfast) for helpful discussions.

\section{Author contributions}

A.K., B.D.E., and R.L.G. carried out the cage synthesis, characterisation, thermal studies, and property investigation of the cage microparticles and Type III porous liquids. A.I.C. and R.L.G. conceived the project, and the paper was written by A.K., B.D.E. and R.L.G. with input from all authors.

\section{Corresponding authors}

Correspondence to R. L. Greenaway or A. I. Cooper

\section{Competing Interests}

The authors declare no conflict of interest. 


\section{References}

1 N. O'Reilly, N. Giri and S. L. James, Chem. Eur. J., 2007, 13, 3020-3025.

2 A. Bavykina, A. Cadiau and J. Gascon, Coord. Chem. Rev., 2019, 386, 85-95.

3 J. Cahir, M. Y. Tsang, B. Lai, D. Hughes, M. A. Alam, J. Jacquemin, D. Rooney and S. L. James, Chem. Sci., 2020, 11, 2077-2084.

4 H. Li, B. Liu, M. Yang, D. Zhu, Z. Huang, W. Chen, L. Yang and G. Chen, Ind. Eng. Chem. Res., 2020, 59, 6154-6163.

5 W. Shan, P. F. Fulvio, L. Kong, J. A. Schott, C. L. Do-Thanh, T. Tian, X. Hu, S. M. Mahurin, H. Xing and S. Dai, ACS Appl. Mater. Interfaces, 2018, 10, 32-36. M. Costa Gomes, L. Pison, C. Červinka and A. Padua, Angew. Chemie Int. Ed., 2018, 57, 1190911912. H. Liu, B. Liu, L. C. Lin, G. Chen, Y. Wu, J. Wang, X. Gao, Y. Lv, Y. Pan, X. Zhang, X. Zhang, L. Yang, C. Sun, B. Smit and W. Wang, Nat. Commun., 2014, 5, 5147-5153.

T. Tozawa, J. T. A. Jones, S. I. Swamy, S. Jiang, D. J. Adams, S. Shakespeare, R. Clowes, D. Bradshaw, T. Hasell, S. Y. Chong, C. Tang, S. Thompson, J. Parker, A. Trewin, J. Bacsa, A. M. Z. Slawin, A. Steiner and A. I. Cooper, Nat. Mater., 2009, 8, 973-978.

10 F. Beuerle and B. Gole, Angew. Chemie Int. Ed., 2018, 57, 4850-4878.

M. Mastalerz, Acc. Chem. Res., 2018, 51, 2411-2422.

A. G. Slater, P. S. Reiss, A. Pulido, M. A. Little, D. L. Holden, L. Chen, S. Y. Chong, B. M. Alston, R. Clowes, M. Haranczyk, M. E. Briggs, T. Hasell, G. M. Day and A. I. Cooper, ACS Cent. Sci., 2017, 3, 734-742.

13 N. Giri, M. G. Del Pópolo, G. Melaugh, R. L. Greenaway, K. Rätzke, T. Koschine, L. Pison, M. F. C. Gomes, A. I. Cooper and S. L. James, Nature, 2015, 527, 216-220.

14 R. L. Greenaway, D. Holden, E. G. B. Eden, A. Stephenson, C. W. Yong, M. J. Bennison, T. Hasell, M. E. Briggs, S. L. James and A. I. Cooper, Chem. Sci., 2017, 8, 2640-2651. 9454-9465. 
Horton, M. B. Hursthouse and S. L. James, Chem. Sci., 2012, 3, 2153-2157.

17 G. Melaugh, N. Giri, C. E. Davidson, S. L. James and M. G. Del Pópolo, Phys. Chem. Chem. Phys., 2014, 16, 9422-9431.

B. D. Egleston, K. V. Luzyanin, M. C. Brand, R. Clowes, M. E. Briggs, R. L. Greenaway and A. I. Cooper, Angew. Chemie Int. Ed., 2020, 59, 7362-7366.

T. Hasell, S. Y. Chong, K. E. Jelfs, D. J. Adams and A. I. Cooper, J. Am. Chem. Soc., 2012, 134, 588-598.

P. Li, H. Chen, J. A. Schott, B. Li, Y. Zheng, S. M. Mahurin, D. E. Jiang, G. Cui, X. Hu, Y. Wang, L. Li and S. Dai, Nanoscale, 2019, 11, 1515-1519.

S. He, L. Chen, J. Cui, B. Yuan, H. Wang, F. Wang, Y. Yu, Y. Lee and T. Li, J. Am. Chem. Soc., 2019, 141, 19708-19714.

Y. Liu, Y. Bai and T. Tian, Materials, 2019, 12, 3984-3991.

23 A. Knebel, A. Bavykina, S. J. Datta, L. Sundermann, L. Garzon-Tovar, Y. Lebedev, S. Durini, R. Ahmad, S. M. Kozlov, G. Shterk, M. Karunakaran, I. D. Carja, D. Simic, I. Weilert, M. Klüppel, U. Giese, L. Cavallo, M. Rueping, M. Eddaoudi, J. Caro and J. Gascon, Nat. Mater., 2020, 1-8.

24 R. E. Mow, A. S. Lipton, S. Shulda, E. A. Gaulding, T. Gennett and W. A. Braunecker, J. Mater. Chem. A, 2020, 8, 23455-23462.

J. Cravillon, S. Münzer, S. J. Lohmeier, A. Feldhoff, K. Huber and M. Wiebcke, Chem. Mater., 2009, 21, 1410-1412.

26 S. Jiang, Y. Du, M. Marcello, E. W. Corcoran, D. C. Calabro, S. Y. Chong, L. Chen, R. Clowes, T. Hasell and A. I. Cooper, Angew. Chemie Int. Ed., 2018, 57, 11228-11232.

27 J. T. A. Jones, T. Hasell, X. Wu, J. Bacsa, K. E. Jelfs, M. Schmidtmann, S. Y. Chong, D. J. Adams, A. Trewin, F. Schiffman, F. Cora, B. Slater, A. Steiner, G. M. Day and A. I. Cooper, Nature, 2011, 474, $367-371$.

28 T. Hasell, S. Y. Chong, M. Schmidtmann, D. J. Adams and A. I. Cooper, Angew. Chemie Int. Ed., 2012, 51, 7154-7157.

29 S. Tothadi, M. A. Little, T. Hasell, M. E. Briggs, S. Y. Chong, M. Liu and A. I. Cooper, CrystEngComm, 2017, 19, 4933-4941. $2019,366,613-620$. 
31 Silicone oil, Sigma-Aldrich, Gillingham, UK, MSDS - 317667,

https://www.sigmaaldrich.com/MSDS/MSDS/DisplayMSDSPage.do?country=GB\&language=en\&pro ductNumber=317667\&brand=ALDRICH\&PageToGoToURL=https\%3A\%2F\%2Fwww.sigmaaldrich.com \%2Fcatalog\%2Fproduct\%2Faldrich\%2F317667\%3Flang\%3Den, (accessed 25 June 2020).

32 M. A. A. Rocha and L. M. N. B. F. Santos, Chem. Phys. Lett., 2013, 585, 59-62.

33 D. Lerche, J. Dispers. Sci. Technol., 2002, 23, 699-709.

34 G. T. Hermanson, in Bioconjugate Techniques, Elsevier, 2013, 549-587.

35 F. Yu, Y. Chen, X. Liang, J. Xu, C. Lee, Q. Liang, P. Tao and T. Deng, Prog. Nat. Sci. Mater. Int., 2017, 27, 531-542.

36 A. Kewley, A. Stephenson, L. Chen, M. E. Briggs, T. Hasell and A. I. Cooper, Chem. Mater., 2015, 27, 3207-3210.

37 L. Chen, P. S. Reiss, S. Y. Chong, D. Holden, K. E. Jelfs, T. Hasell, M. A. Little, A. Kewley, M. E. Briggs, A. Stephenson, K. M. Thomas, J. A. Armstrong, J. Bell, J. Busto, R. Noel, J. Liu, D. M. Strachan, P. K. Thallapally and A. I. Cooper, Nat. Mater., 2014, 13, 954-960. 